Swarthmore College

Works

$4-1-2012$

\title{
Revisiting Incentive Effects In Workers' Compensation: Do Higher Benefits Really Induce More Claims?
}

\author{
Erin Todd Bronchetti \\ Swarthmore College, ebronch1@swarthmore.edu
}

M. Mclnerney

Follow this and additional works at: https://works.swarthmore.edu/fac-economics

Part of the Economics Commons

Let us know how access to these works benefits you

\section{Recommended Citation}

Erin Todd Bronchetti and M. McInerney. (2012). "Revisiting Incentive Effects In Workers' Compensation: Do Higher Benefits Really Induce More Claims?". Industrial And Labor Relations Review. Volume 65, Issue 2. 286-315. DOI: $10.1177 / 001979391206500205$

https://works.swarthmore.edu/fac-economics/29

This work is brought to you for free by Swarthmore College Libraries' Works. It has been accepted for inclusion in Economics Faculty Works by an authorized administrator of Works. For more information, please contact myworks@swarthmore.edu. 


\section{HEINONLINE}

Citation: 65 Indus. \& Lab. Rel. Rev. 2862012

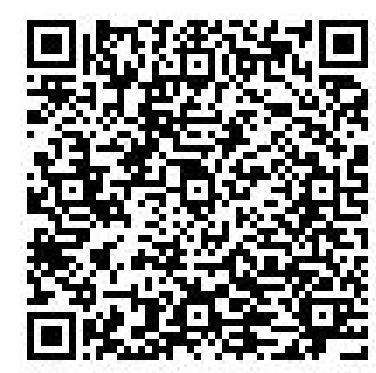

Content downloaded/printed from

HeinOnline (http://heinonline.org)

Mon Aug 4 10:00:112014

-- Your use of this HeinOnline PDF indicates your acceptance of HeinOnline's Terms and Conditions of the license agreement available at http://heinonline.org/HOL/License

-- The search text of this PDF is generated from uncorrected OCR text.

-- To obtain permission to use this article beyond the scope of your HeinOnline license, please use:

https://www.copyright.com/ccc/basicSearch.do?

\&operation $=$ go\&search $\mathrm{Type}=0$

\&lastSearch $=$ simple\&all=on\&titleOrStdNo=0019-7939 


\title{
REVISITING INCENTIVE EFFECTS IN WORKERS' COMPENSATION: DO HIGHER BENEFITS \\ REALLY INDUCE MORE CLAIMS?
}

\author{
ERIN TODD BRONCHETTI AND MELISSA MCINERNEY*
}

\begin{abstract}
An important question to ask regarding social insurance programs such as workers' compensation (WC) is to what extent do higher benefits lead to more claims? The authors of this study revisit incentive effects of WC, using 25 years of data (1977-2004) from the March Current Population Survey (CPS) to estimate the relationship between WC cash benefit levels and the frequency of WC receipt. Providing new evidence on the subject, they demonstrate that conclusions regarding workers' incentives to claim benefits differ dramatically depending upon how one controls for the confounding influence of an individual's past earnings. The authors' expanded empirical specifications, which include flexible earnings controls, yield benefit-participation elasticities smaller than 0.1 . Their findings suggest that WC claims are not particularly responsive to changes in benefit levels and that labor supply disincentives may warrant less concern than economists or policymakers have typically exhibited. The authors also find that WC receipt was less responsive to benefit variation after 1990 than in previous years.
\end{abstract}

Social insurance programs that provide income support during periods of Ononwork are of concern to economists because of the labor supply disincentives inherent in their design. State workers' compensation (WC) programs, which provide cash benefits and cover medical costs for workers who are injured or become ill on the job, are no exception. There is a substantial literature that examines the effects of variation in WC cash benefits on injury rates, claims numbers, and the duration of claims. ${ }^{1}$

Our study revisits the question of incentive effects in WC by using 25 years of matched March Current Population Survey (CPS) data to estimate the relationship between WC cash benefit generosity and the frequency of WC receipt. Krueger (1990) used data from two years in the 1980s to document a large elasticity of WC receipt with respect to benefits $(0.74)$, a widely cited parameter. In general, the prevailing understanding is that worker participation in the program is quite responsive to changes in benefit generosity.

\footnotetext{
*Erin Todd Bronchetti is Assistant Professor in the Department of Economics, Swarthmore College. Melissa McInerney is Assistant Professor in the Department of Economics, College of William and Mary.

A data appendix with additional results and copies of the computer programs used to generate the results presented here are available from Professor McInerney: mpmcinerney@wm.edu.

'Fortin and Lanoie (1998) and Krueger and Meyer (2002) provide thorough reviews.
} 
Yet, closer inspection of the research on this topic suggests no real consensus on the magnitude or economic significance of this response. ${ }^{2}$

We contribute to understanding the relationship between benefit and receipt in several ways. First, we use matched March CPS data spanning the period from 1977-78 to 2003-04 to provide an estimate of the elasticity of WC receipt with respect to benefits based on the longest nationally representative set of micro data ever used to study WC. Existing research proffers a wide range of estimates of the effect of variation in WC benefits on injury and claim rates, but most of this research relies on the use of aggregated state-level, or state-by-industry-level, data. The few studies that employ nationally representative, individual-level data focus primarily on the 1980s. An updated estimate of this relationship is warranted given dramatic changes in WC trends since 1990.

Second, we have improved upon the methodology used in previous research to control for differences in propensities to claim WC among individuals with different pre-injury earnings. Because weekly $\mathrm{WC}$ benefits are a function of a worker's average weekly earnings in the year before injury, in order to produce an unbiased estimate of the benefit elasticity, it is crucial to control carefully for the influence of prior earnings on WC participation. We show that typical methods of accounting for pre-injury earnings are not sufficient and that including more flexible controls dramatically reduces the estimated relationship between benefit levels and program participation. In fact, when we control for differences in propensities to claim WC among individuals with different earnings by using either a simple linear spline in pre-injury earnings or a series of indicator variables for different points on the earnings distribution, variation in benefit generosity appears to have little to no impact on the likelihood of WC receipt. These results clearly challenge the prevailing wisdom that workers are highly responsive to changes in WC generosity and suggest that labor supply disincentives, or moral hazard, in WC may not warrant as much concern as previously thought. Our findings could also have important implications for empirical analyses of other social insurance programs in which benefits are a direct function of previous earnings.

Our third contribution to the literature is our examination of the effects on program participation of changes in legislated program parameters, which policymakers can directly influence and which may be more salient to workers. We find no evidence of increased claiming when key WC parameters (i.e., the minimum benefit, the maximum benefit, and the replacement rate) become more generous. Consistent with our other findings, this suggests that perhaps policymakers can increase program generosity at a lower cost than suggested by previous estimates.

${ }^{2}$ The existing literature on the relationship between $W C$ receipt and benefit levels provides evidence of a positive relationship, with 0.18 (Hirsch, Macpherson, and Dumond 1997) being the lowest estimated benefit elasticity. The extant work on the responsiveness of injury rates to variation in WC benefits provides estimated elasticities ranging from zero (Guo and Burton 2010) to over 1.0 (Butler and Worrall 1983). 
Finally, our results inform a puzzle seen in the aggregate trends in the 1990s. Between 1990 and 2003, the share of workers beginning to receive WC cash benefits dropped in half, while average benefits rose. The literature provides suggestive evidence that workers were less responsive to changing benefit levels after 1990. But it is unclear whether the relationship between WC participation and cash benefit levels changed over time or whether the disparate results are a product of different methodologies. ${ }^{3}$

Incorporating individual-level data from the 1990s and early 2000s, we help clarify these divergent trends. Our study complements the research of Guo and Burton (2010), who estimate the relationship between WC benefits and state-level injury rates for the pre-1990 and post-1990 periods. Some of our findings are similar to theirs; we both estimate a benefit elasticity that is closer to zero than suggested in previous research. Once we flexibly control for an individual's prior earnings, however, we document a substantial decline in responsiveness to benefits in the post-1990 period.

\section{Background on Workers' Compensation}

State WC programs are the oldest and one of the largest forms of social insurance in the United States. WC laws require that firms obtain insurance or self-insure to provide to workers who become injured or ill on the job a state-mandated amount of cash benefits, medical care, and rehabilitation services when necessary. Coverage extends to almost $94 \%$ of the American wage and salaried workforce, and a worker becomes eligible to receive WC as soon as he or she enters covered employment.

While in recent years researchers have paid somewhat less attention to WC than to other social insurance programs, the importance of WC for workers and employers cannot be denied. In 2008 , WC programs paid $\$ 57.6$ billion in benefits (including medical costs), and employer costs for WC amounted to $\$ 78.9$ billion (Sengupta, Reno, and Burton 2010). ${ }^{4}$ As a source of support for disabled workers, WC is surpassed in size only by Social Security disability insurance and Medicare. Throughout the 1990s and early 2000 s, WC expenditures were larger than those of unemployment insurance (UI), Supplemental Security Income, cash welfare, or food stamps (U.S. House of Representatives, 2004).

\section{Workers' Compensation Benefits and Incentives for Workers}

There is substantial variation across states in the legislated parameters that determine WC benefits; however, all states calculate temporary total dis-

\footnotetext{
${ }^{3}$ Ruser, Pergamit, and Krishnamurty (2004) and Neuhauser and Raphael (2004) estimate a smaller relationship between cash benefit levels and WC participation. Their outcome of interest, however, is WC take-up, conditional on an injury, not the overall responsiveness of WC participation to changes in benefits.

${ }^{4} \mathrm{Of}$ the $\$ 57.6$ billion in total benefits paid out to workers, about half went to indemnity benefits, while the remainder went to medical costs.
} 
ability (TTD) benefits, the focus of this study, similarly. An injured worker's weekly TTD benefit will equal a fraction of the worker's pre-injury gross weekly earnings-the replacement rate is typically two-thirds-subject to minimum and maximum benefit amounts that vary significantly across states. Most states' TTD benefit schedules are similar to California's in that they award workers with earnings less than the state minimum (\$126 in California) their full weekly earnings. Those earning between $\$ 126$ and $\$ 189$ per week receive the minimum benefit of $\$ 126$. Most injured workers in California receive two-thirds of their pre-tax weekly earnings, while workers with weekly earnings above $\$ 903$ receive the maximum, $\$ 602$. A smaller number of states set a strict minimum benefit; for example, in Ohio, workers earning less than the minimum benefit of $\$ 214$ receive a weekly benefit equal to $\$ 214$, regardless of how low their pre-injury earnings were. ${ }^{5}$

State-determined waiting periods range from three to seven days and act as a deductible that workers must pay before receiving indemnity benefits. Workers are later compensated for this time if their injury persists beyond the retroactive period, which is usually a few weeks.

Table 1 displays, for a representative set of states, variation in legislated benefit parameters, waiting and retroactive periods, and measures of state WC generosity for the CPS sample used in our analysis. In most states, the rate of wage replacement provided by WC benefits is two-thirds; however, in some states (e.g., Connecticut and Iowa), replacement rates are higher because benefits are calculated as a percentage of after-tax earnings.

The most important source of cross-state variation in benefit generosity is the maximum benefit level; for instance, while Illinois had a maximum weekly benefit of $\$ 1,004$, in the same year, injured workers in New York received a maximum of $\$ 400$ per week. Whereas only 12 percent of Illinois workers in our sample have earnings high enough to be subject to their state's maximum benefit, 55.5 percent of New York workers would be subject to its $\$ 400$ maximum. Nominal replacement rates can be significantly lower than two-thirds in states with low maximum benefit levels (e.g., Mississippi) and higher than two-thirds in states with high minimum benefit levels (e.g., Pennsylvania).

Unlike UI benefits, WC cash benefits are exempt from income or payroll taxation, which can produce a much more generous after-tax replacement rate. In fact, after-tax replacement rates near or above 100 percent are not uncommon (Meyer 2002), and average after-tax replacement rates are above 90 percent in some states (e.g., Ohio and Pennsylvania).

The primary state policy levers to alter WC benefits include changes in the level of the maximum, the minimum, and the replacement rate. The most common changes in legislated benefit generosity are increases and decreases in the maximum and minimum. States can also change the re-

\footnotetext{
${ }^{5} \mathrm{~A}$ few states, like Colorado, have a $\$ 0$ minimum, so that all workers are paid two-thirds of their average pre-injury wage up to the maximum benefit level. Even less common are TTD schedules like Hawaii's, in which there are two effective minimum benefit levels.
} 


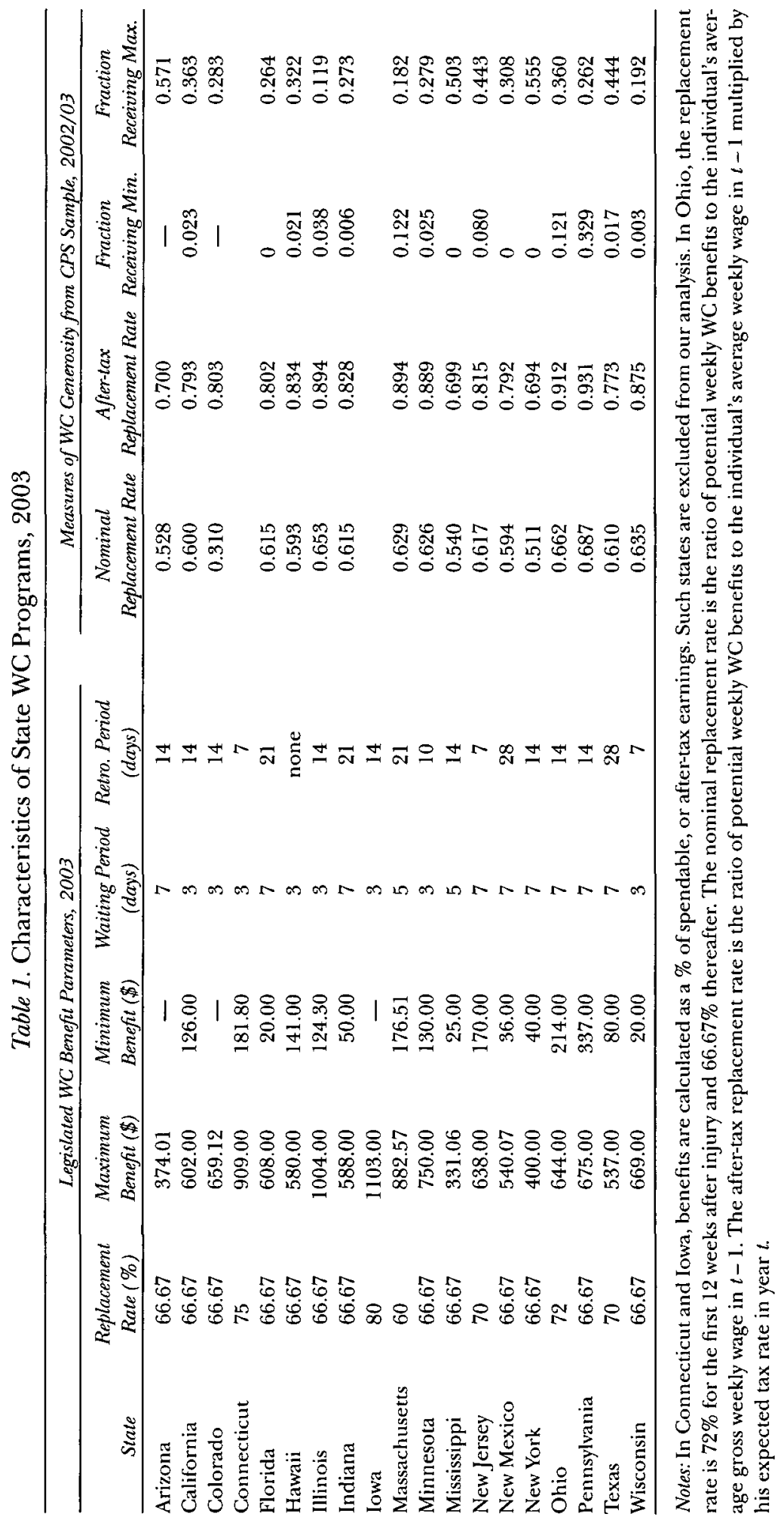


placement rate, which corresponds to the sloped portion of the benefit schedule. These types of changes are much less common but impact a large share of workers. ${ }^{6}$

Changes in WC benefits can affect the frequency of WC receipt by altering the incentives for both workers and employers. At the employee level, increased benefit generosity reduces the cost of an injury and may cause workers to devote less effort to on-the-job safety or illness prevention. Several earlier studies provide evidence of a positive relationship between WC benefits and the frequency of nonfatal workplace injuries and illnesses. ${ }^{7}$ In recent work, however, Guo and Burton (2010) use aggregate state-level data on injury rates from the Bureau of Labor Statistics (BLS) to find an estimated benefit elasticity that is much closer to zero. Increases in WC benefits may also lead to more frequent fraudulent reporting of injuries or illnesses that do not exist or occurred outside of work. ${ }^{8}$

Even if benefit generosity does not affect workplace safety or increase fraudulent reporting of injuries and illnesses, more generous benefits can cause more WC claims by increasing take-up among injured workers. When benefits are higher, the benefits of filing for WC are more likely to outweigh the costs, which include forgone labor income, transaction costs for filing a claim, and any stigma or costly reputation effect of receiving WC. ${ }^{9}$

Regardless of the dimension along which benefit variation affects worker behavior, the prediction of a positive relationship between benefits and WC receipt is unambiguous.

\section{Workers' Compensation Costs and Incentives for Firms}

The premiums paid by firms that purchase WC insurance are an increasing function of the risk involved in the employer's business (base premium) and the employer's loss history (experience rate). The smallest employers pay the base premium, and WC premiums are experience rated for larger or riskier employers. In the largest firms, premiums are almost perfectly experience-rated, essentially reflecting only firms' past losses (Krueger 1991).

With experience-rated WC premiums, higher benefit levels increase the costs associated with a firm's accident experience. Taking the safety effort of employees as given, a firm has more incentive to increase spending on safety

\footnotetext{
${ }^{6}$ Between 1978 and 2004, we document only 8 instances of increases in the replacement rate (generally from 66.67 to $70.00 \%$, or 60.00 to $66.67 \%$ ) and 5 instances of decreases in the replacement rate. As seen in Figure 2, aggregate generosity increased between 1977 and 2003, with the average nominal replacement rate rising from 0.56 in 1977 to 0.61 in 2003. This increase reflects changes in the maximum, minimum, replacement rate, and earnings distribution.

${ }^{7}$ See, e.g., Chelius (1982), Ruser (1985, 1991), Moore and Viscusi (1989), Worrall and Butler (1988).

${ }^{8}$ The evidence on the extent of fraudulent reporting in WC is mixed (see Smith 1990; Butler and Worrall 1991; Card and McCall 1996; and Ruser 1998).

${ }^{9}$ See Biddle and Roberts (2003); Neuhauser and Raphael (2004); Ruser et al. (2004) and Lakdawalla, Reville, and Seabury (2007) for studies that address the responsiveness of take-up to variation in benefits.
} 
or to discourage claims when benefits rise. ${ }^{10}$ Thus, if only firm behavior were affected by increases in WC benefits, we would expect a negative relationship between benefits and WC claims. The existing evidence, however, suggests that the effects of higher benefits on worker behavior outweigh those for firms. ${ }^{11}$

Finally, note that if benefit variation has no effect or has perfectly offsetting incentive effects on the behavior of workers and firms, insurance costs should rise in direct proportion to benefits. Krueger and Burton (1990) find the cost-benefit elasticity to be greater than one but smaller than previous estimates of the claims-benefit elasticity would suggest. This implies that increases in WC benefits induce claims for less costly impairments or that existing estimates of the benefit elasticity overstate the true relationship between benefit generosity and WC receipt or both.

The empirical relationship between WC benefits and the rate of participation in WC incorporates all the incentive effects for workers and firms just described. Several studies have documented a positive elasticity between benefits and the overall frequency of claims. Like the authors of these studies, we make no attempt to identify separately the effects of benefit variation on the behavior of workers and firms. Rather, since policymakers can affect statutory benefits but cannot directly influence decisions about safety or take-up, the underlying argument is that the policy parameter of interest is the impact of changes in legislated WC benefits on the overall rate of WC receipt.

\section{Trends in Workers' Compensation}

Figure 1 displays the frequency of WC receipt by year for the CPS sample used in our study. For the period from 1977 through 1989, recipiency rates ranged from $1.4 \%$ to $2.0 \%$ of the population, but after 1990 , a clear pattern of declining WC receipt emerges, and the participation rate drops as low as 0.7 percent. Some of this decline may reflect the fact that workplaces became safer: the injury rate fell in every industry, and there was a shift in employment toward safer industries.

During this same period, both the average maximum WC benefit and the average nominal replacement rate rose substantially, as shown in Figure 2. At a cursory glance, this observation is in stark contrast to the conventional wisdom that $\mathrm{WC}$ receipt increases with program generosity.

\section{Data}

Our data come from the March Annual Demographic Supplement to the CPS, which contains extensive information on sources of income, demo-

\footnotetext{
${ }^{10}$ Indeed, Chelius and Smith (1983), and Ruser $(1985,1991)$ provide evidence of a smaller relationship between benefits and nonfatal injury rates for larger, more highly experience-rated firms.

${ }^{11}$ See Chelius (1982), Worrall and Butler (1988), and Ruser (1985, 1991). Of course, insurers also face incentives. In this context, insurer and employer incentives are quite similar.
} 
Figure 1. The Frequency of WC Receipt, 1977-2003

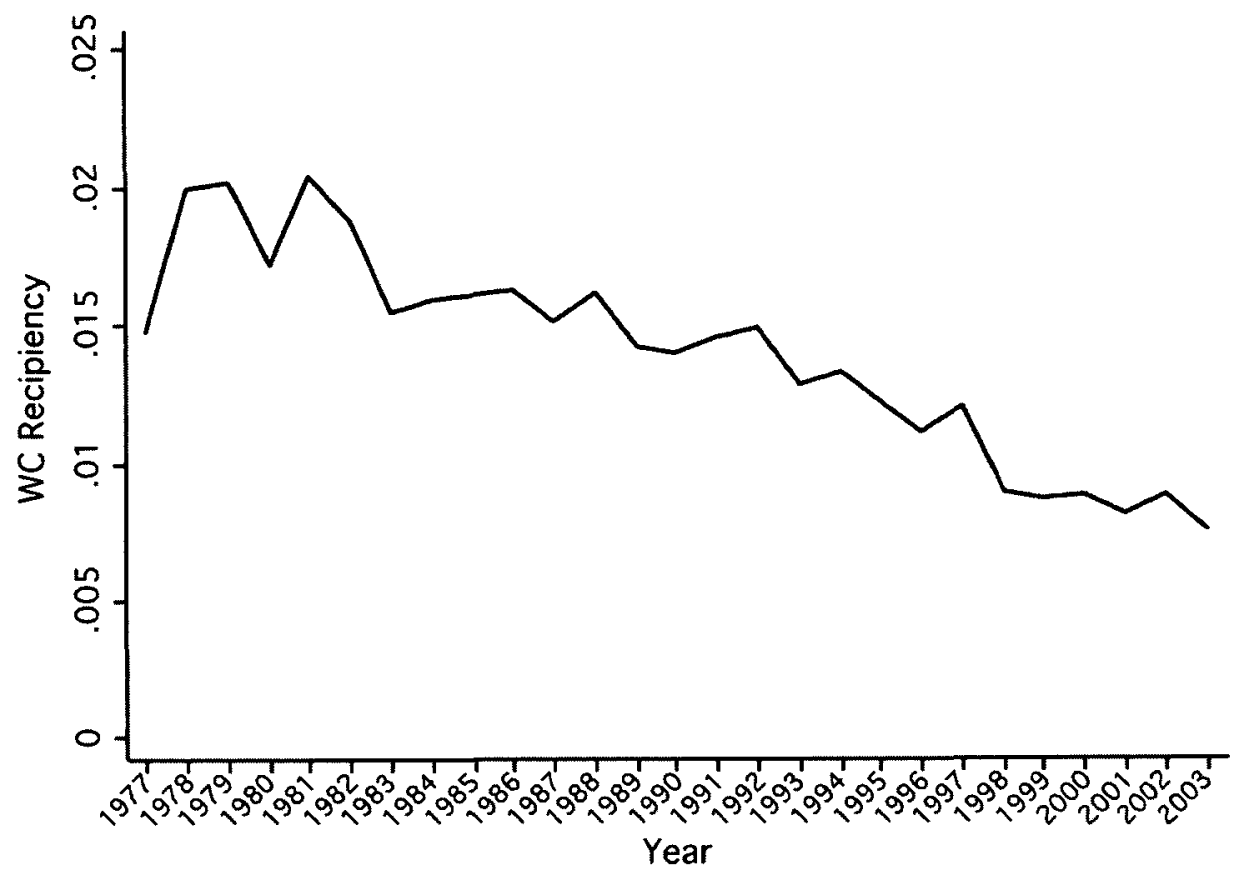

Source: Authors' calculations from CPS sample.

Figure 2. Average Maximum Weekly Benefit and Nominal Replacement Rate, 1977-2003

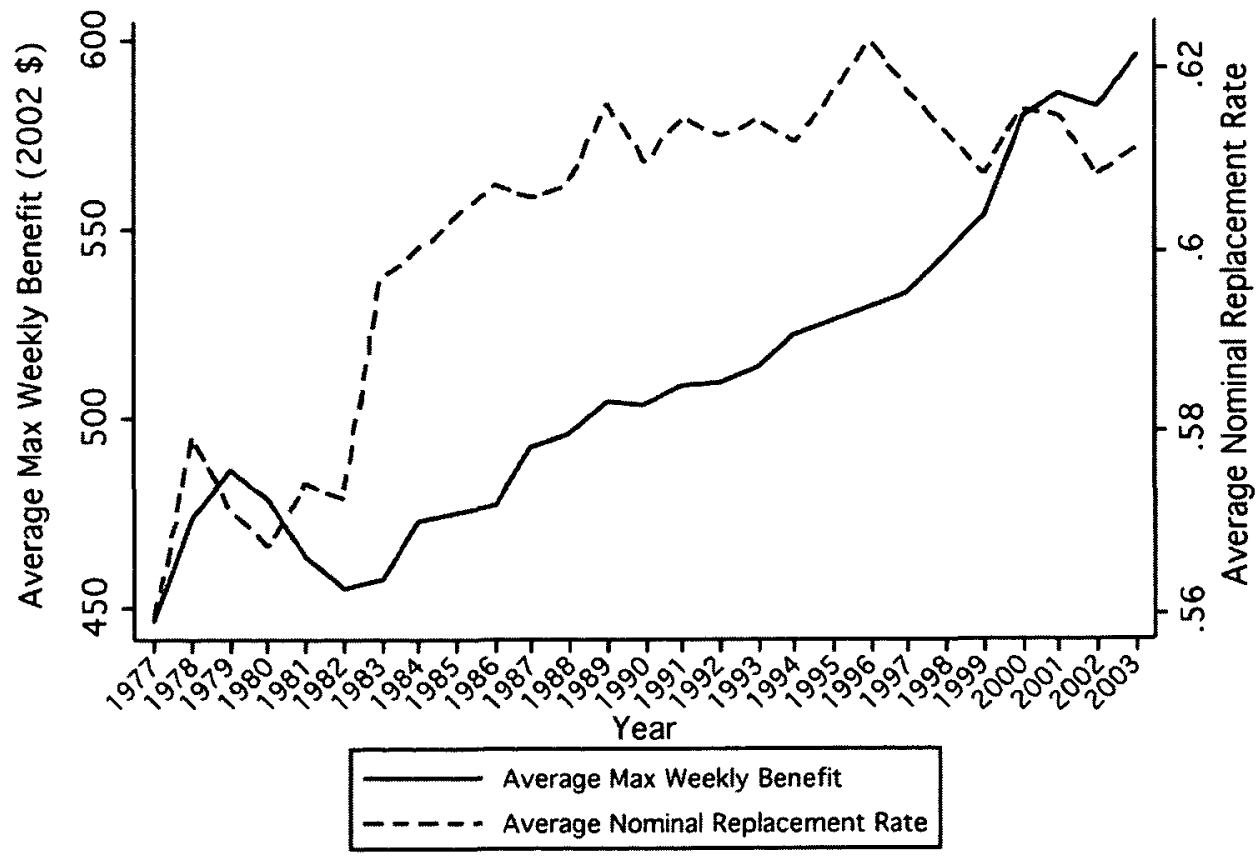


graphic characteristics, and employment. The ability to use the March CPS as a two-year panel is especially useful for our study, which analyzes transitions into $W C$, where the dependent variable is the probability of receiving $W C$ in year $t$ conditional on not having received benefits in year $t-1 .{ }^{12}$ Moreover, detailed information on earnings and employment in the year before WC receipt permits the estimation of participation elasticities with respect to both benefits and pre-injury wages. ${ }^{13}$

Our sample pools data on individuals from 25 years of matched March CPS files for the survey years $1977 / 78-1984 / 85,1986 / 87-1994 / 95$, and $1996 / 97-2003 / 04 .{ }^{14}$ To match observations across years, we adapt the methodology in Madrian and Lefgren (1999). ${ }^{15}$ The resulting data set observes each individual in two consecutive years.

The final sample contains individuals ages 18 to 64 (in year $t-1$ ) who report having worked at least one week in year $t-1$ but did not receive WC benefits in that year. We restrict the sample to heads of household and spouses because the relationship between WC benefit generosity and WC receipt may be fundamentally different for a teenager or an elderly parent. ${ }^{16}$ We limit the sample to civilians working in nonpublic, non-self-employed jobs in year $t-1$. We exclude workers in the agriculture or domestic services industries, sectors which are not likely to be covered by WC, and railroad workers, longshoremen, harbor workers, and seamen because they are likely to be covered under federal programs. We also exclude individuals in states in which benefits are based on after-tax earnings instead of pretax labor earnings. The pooled sample contains 269,514 individuals.

Next, we match the sample to a database we have constructed that contains information on all state WC laws and benefit parameters for the years from 1977 to $2003 .{ }^{17}$ For each individual in the sample, we calculate a potential weekly WC benefit for year $t$, based on his or her average gross weekly earnings in year $t-1$, the replacement rate, and the maximum and minimum benefit amounts in the worker's state during year $t$. The potential benefit is also adjusted for number of dependents and marital status for in-

\footnotetext{
${ }^{12} \mathrm{CPS}$ respondents are interviewed for four months, excluded for eight months, and then interviewed for four more months. Ignoring attrition and migration, up to half of the observations in a March CPS should be able to be matched to their previous year's record. The CPS does not follow households that move.

${ }^{19} \mathrm{An}$ important predictor of injury is having suffered a prior injury. If a worker's earnings-and corresponding expected benefit-fall after a work-related injury, we might expect our estimated benefit elasticity to be biased downward to the extent that our sample contains some workers who have been injured previously. Unfortunately, we cannot observe whether workers in the CPS have suffered prior injuries, but we restrict our sample to those who were not receiving WC in year $t-l$.

${ }^{14}$ Beginning in 1980 , the CPS used improved methods to identify WC receipt. Our main results are very similar when looking only at years after 1980 .

${ }^{15}$ The survey years correspond to calendar years 1976/77-1983/84, 1985/86-1993/94, and 1995/96$2002 / 2003$. It was not possible to match for the period from 1985 to 1986 because of changes to geographic indicators. It was also not possible to match from 1995 to 1996 because of revisions in the census household numbering scheme.

${ }^{16}$ Our main qualitative results are robust to the inclusion of all workers.

${ }^{17}$ This information is compiled from consecutive issues of the U.S. Chamber of Commerce's Analysis of Workers' Compensation Laws (1977-2003).
} 
dividuals in states with such allowances. We use state TTD benefit schedules to calculate benefits because all WC claims are initially filed as TTD cases.

We compute an individual's weekly earnings in the previous year by dividing his or her annual wage and salary income (before deductions) in $t-1$ by the number of weeks worked in that year. We use the previous year's weekly earnings to calculate the potential benefit because states calculate benefits using the worker's average pre-tax weekly earnings from some subset of the 52-week pre-injury period and because weeks worked and earnings in year $t-1$ would not have been affected by an injury that occurred in year $t$. Note that it is possible that an individual's weekly earnings in year $t-1$ are correlated with whether that person receives WC in year $t$ if workers in riskier jobs receive compensating wage differentials. We include 9 1-digit occupation dummies and 41 2-digit industry dummies to control for such compensating differentials.

Because WC cash benefits are not subject to income or payroll taxation, the real benefit of receiving WC is also a function of the tax rate. We employ TAXSIM to simulate tax rates (i.e., the sum of federal, state, and FICA rates) for individuals in our sample. Using TAXSIM to derive more accurate tax rates for individuals should improve upon the estimation in previous research, in which tax rates are based on a classification of individuals into a small number of tax brackets or are not explicitly considered. TAXSIM permits the calculation of a tax rate for every individual in the sample based on information about income, dependents, and filing status. ${ }^{18}$

Table 2 presents descriptive statistics for recipients versus nonrecipients in our sample; means are calculated by pooling the years of data. Approximately $1.3 \%$ (or 3,608) of the individuals in the sample take up WC during the year. WC recipients earn less per week in the year before receiving WC than nonrecipients but have a slightly higher average weekly benefit entitlement. WC claimants are more likely to be male, slightly older, and less educated than nonrecipients, and they are more likely to work in blue-collar jobs and in industries with a higher risk of injury, like manufacturing, transportation, or construction.

\section{Determinants of Workers' Compensation Recipiency}

We estimate probit models in which the dependent variable equals 1 if an individual begins receiving WC in year $t$. The model takes the form:

$$
\begin{aligned}
\mathrm{P}\left(w c_{i s t}=1\right)= & \Phi\left(\beta_{1} \ln \left(B E N_{i s t}\right)+\beta_{2} \ln \left(\text { wage }_{i, t-1}\right)+\beta_{3} \ln \left(1-\operatorname{tax}_{i s t}\right)\right. \\
& \left.+\beta_{4} \text { wait }_{s t}+\beta_{5} \text { retro }_{s t}+\delta X_{i, t,-1}+\gamma_{s}+\tau_{t}+\varepsilon_{i s t}\right)
\end{aligned}
$$

\footnotetext{
${ }^{18}$ It is important to note that the input variables used to compute marginal tax rates are values for year $t-1$. Therefore the simulated marginal tax rates for recipients should not be confounded by WC receipt or by reduced earnings due to injury. But we calculate tax rates according to the laws for year $t$ so that the simulated tax rate represents the rate an individual would face on wage income in year $t$. Finally, we exclude sources of income for which the CPS definition changed over the period from 1977 to 2003 (e.g., property income, dividend income, property taxes, capital gains, and UI benefits).
} 
Table 2. CPS Sample Characteristics by WC Recipiency

\begin{tabular}{lrrrrrr}
\hline & \multicolumn{3}{c}{$A l l$} & \multicolumn{2}{c}{ Recipients } & Nonrecipients \\
\hline WC $=1$ & 0.0134 & $(0.11)$ & & & & \\
Weekly WC benefit, simple min. & 392.49 & $(155.87)$ & 392.78 & $(142.04)$ & 392.49 & $(156.05)$ \\
Weekly WC benefit & 391.02 & $(157.64)$ & 392.09 & $(142.86)$ & 391.01 & $(157.84)$ \\
Average weekly earnings $(t-1)$ & 759.06 & $(497.68)$ & 705.14 & $(371.63)$ & 759.79 & $(499.14)$ \\
Marginal tax rate (incl. FICA) & 39.99 & $(9.63)$ & 39.26 & $(9.87)$ & 40.00 & $(9.63)$ \\
Male & 0.55 & $(0.50)$ & 0.66 & $(0.47)$ & 0.55 & $(0.50)$ \\
Age & 41.43 & $(11.09)$ & 40.93 & $(11.22)$ & 41.44 & $(11.09)$ \\
Education (years) & 13.05 & $(2.53)$ & 12.05 & $(2.27)$ & 13.06 & $(2.53)$ \\
White & 0.88 & $(0.32)$ & 0.89 & $(0.31)$ & 0.88 & $(0.32)$ \\
Black & 0.07 & $(0.26)$ & 0.07 & $(0.26)$ & 0.07 & $(0.26)$ \\
Hispanic and other & 0.02 & $(0.15)$ & 0.02 & $(0.15)$ & 0.02 & $(0.15)$ \\
Never married & 0.09 & $(0.28)$ & 0.08 & $(0.27)$ & 0.09 & $(0.28)$ \\
Divorced, widowed, or separated & 0.12 & $(0.32)$ & 0.13 & $(0.34)$ & 0.12 & $(0.32)$ \\
Married & 0.80 & $(0.40)$ & 0.79 & $(0.41)$ & 0.80 & $(0.40)$ \\
Average weekly hours worked $(t-1)$ & 40.53 & $(9.88)$ & 41.16 & $(8.25)$ & 40.52 & $(9.90)$ \\
Earnings of other family members $(t-1)$ & 24,928 & $(32655)$ & 19,466 & $(24789)$ & 25,002 & $(32742)$ \\
Interest, dividend, rental income $(t-1)$ & 1,167 & $(5177)$ & 711 & $(3651)$ & 1,173 & $(5194)$ \\
Estimated home equity ( $t-1)$ & 3,933 & $(4600)$ & 3,638 & $(4460)$ & 3,936 & $(4601)$ \\
"Blue-collar" occupation & 0.34 & $(0.47)$ & 0.63 & $(0.48)$ & 0.33 & $(0.47)$ \\
Industry: Construction, manufacturing & 0.41 & $(0.49)$ & 0.59 & $(0.49)$ & 0.44 & $(0.49)$ \\
$\quad$ mining, or transportation & & & & & & 265,906 \\
N & 269,514 & & 3,608 & &
\end{tabular}

Notes: Figures are unweighted sample means with standard deviations in parentheses. Recipients are workers who report receiving WC income in year $t$, conditional on not having received WC in the previous year. All dollar amounts are in 2002 dollars. Blue-collar occupations are craft, transport operator, laborer, or operator.

where $P\left(w c_{i s t}=1\right)$ is the probability that individual $i$ receives WC in year $t$ (conditional on not having received WC in year $t-1$ ), $\Phi$ is the normal cumulative distribution function, $B E N_{i s t}$ is the potential weekly WC benefit for which individual $i$ is eligible, wage $_{i, t-1}$ is the worker's average gross weekly earnings in year $t-1$, and $\operatorname{tax}_{i s t}$ is the total marginal tax rate an individual would pay in year $t$ based on his $t-1$ income and filing characteristics. The variables $w_{a i t} t_{i s}$ and retro $_{i s t}$ are the number of days in the waiting and retroactive periods, respectively, in individual $i$ s state and year. The vector $X_{i t, l-1}$ contains characteristics of the worker in year $t$, including his or her age, education, race, and marital status, as well as dummies for occupation and industry in $t-1$. Finally, $\gamma_{s}$ is a set of state fixed effects, and $\tau_{t}$ is a set of year effects. ${ }^{19}$

We begin by replicating the results in Krueger (1990) and then apply the same approach to our much larger data set. These results are displayed in Table 3. Here, the parsimonious model (model 1) controls only for WC pa-

\footnotetext{
${ }^{19}$ One might be concerned that the inclusion of state fixed effects does not leave enough variation in the benefit variable to identify benefit effects. One way to test for sufficient identifying variation is to assess the amount of within-state variation in benefits. Following Chernew, DeCicca, and Town (2008), we regress the benefit variable on a full set of state and year dummies and compute the variation inflation factor (VF), equal to the reciprocal of one minus the R-squared of the regression. The VIF is about 1.1, well below the conventional threshold of 10.0 . This indicates sufficient within-state variation in benefits.
} 


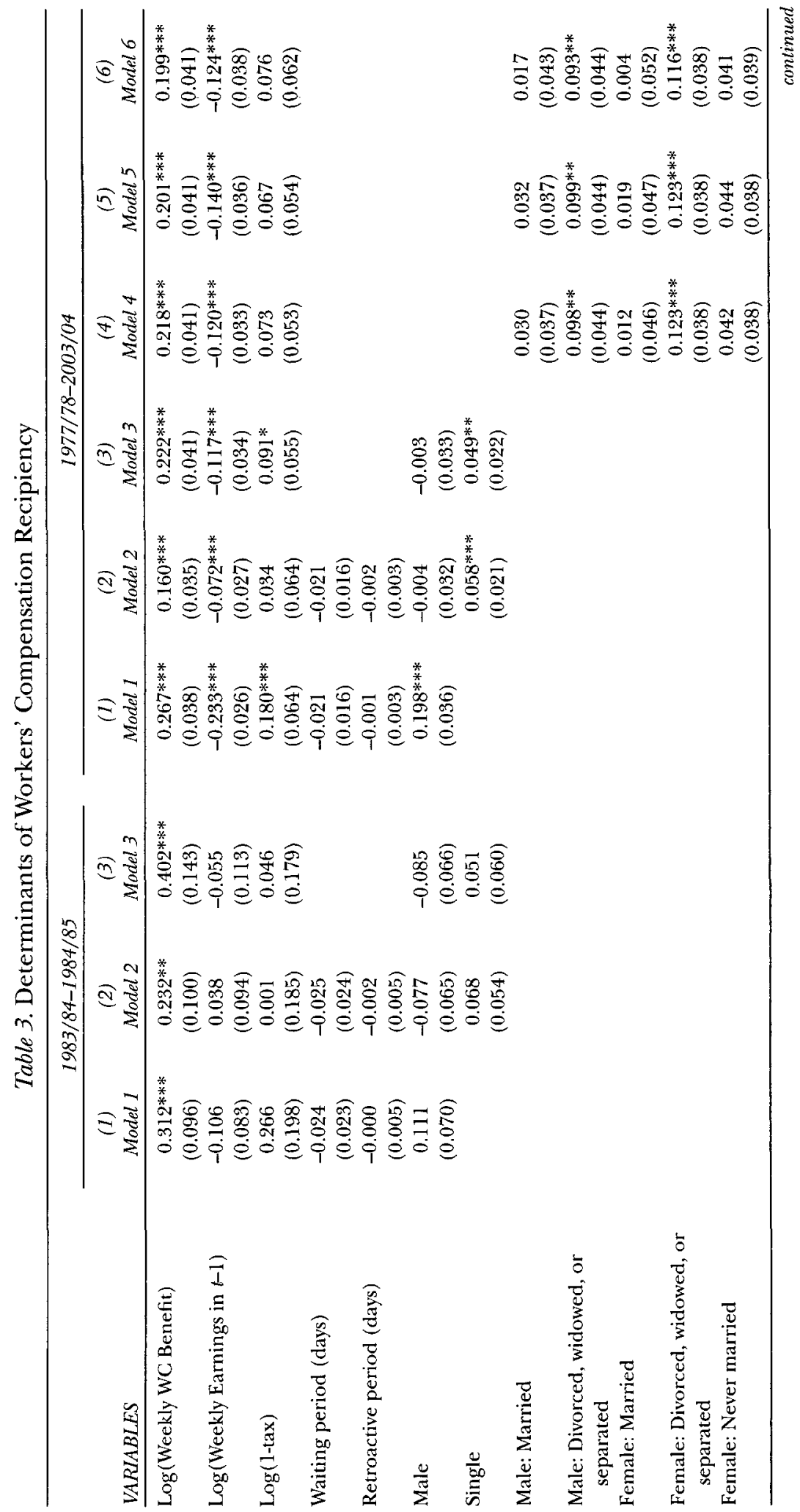




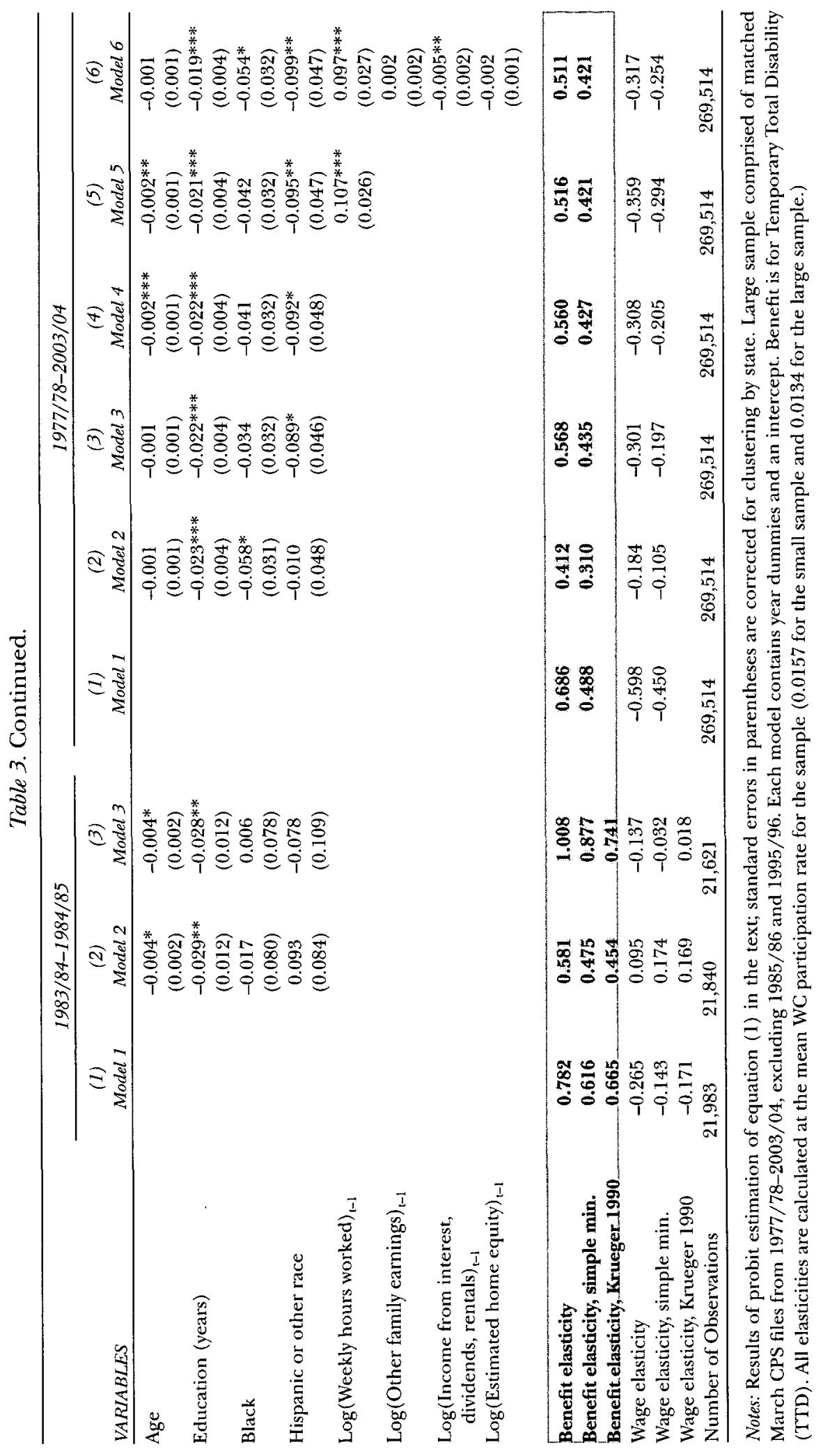


rameters and the individual's weekly earnings, marginal tax rate, and gender, as well as a full set of year dummies. The next model adds demographic controls and occupation and industry dummies. The third model adds a set of 43 state dummies; identification here depends on within-state changes in WC laws, nonlinearities in the benefit formulas, and individual benefit variation within states (e.g., due to dependent allowances).

The probit results in the first three columns can be directly compared to those in Krueger (1990), as can the corresponding benefit and wage elasticities displayed in the bottom panel of the table..0 The reported coefficients and the corresponding benefit elasticities in the top row of this panel are from probit models in which the potential WC benefit is calculated to allow for more complex treatment of minimum benefits in states that do not have a binding minimum (i.e., states like California). Benefit elasticities in the second row are from estimation of identical models in which the benefit variable is calculated ignoring these complexities; that is, we assign the legislated minimum to those earning less than the minimum in all states (i.e., treat all states like Ohio). The latter method is, as best we can discern, the method used in most previous research. But because the complexities in benefit formulas are an important source of variation in WC benefits, hereafter we emphasize our results from the more rigorous method for calculating WC benefits. In short, it appears that these two years of data yield relatively large estimates of the benefit elasticity, in the range of 0.6 to 1.0 , according to our probit results.

When we apply these methods to our larger data set, which contains observations from 1977/78-2003/04, we conclude that 1983/84-1984/85 were somewhat peculiar years with respect to the benefit elasticity and other covariates. Specifically, the results for the larger data set imply benefit elasticities approximately half the size of our corresponding estimates for the period from 1983/84 to 1984/85. We also estimate a negative and statistically significant impact of lagged weekly earnings on WC receipt. We find an unexpected positive effect of the net-of-tax rate on WC receipt, which we address in expanded versions of the model. Finally, unlike the conclusions of previous studies, our results do not indicate that the waiting period has a significant effect on receipt.

Next, we address the possibility that the benefit, wage, and tax coefficients are biased due to omitted variables. In model 4 , we interact marital status (i.e., never married, divorced/widowed/separated, or married) with gender for a fuller set of controls. The coefficients on these variables indicate that divorced/widowed/separated workers are significantly more likely than others to receive WC. Although including these controls does not change the benefit or wage elasticities remarkably, the coefficient on the tax variable drops to 0.07 and is no longer statistically different from zero. When we

\footnotetext{
${ }^{20}$ Despite our attempt to use the same sample selection criteria, we end up with a slightly larger sample for the period from 1983/84 to 1984/85, perhaps because of improved techniques for matching individuals across years of the March supplements.
} 
estimate the model separately for men and women, the resulting benefit elasticities do not differ significantly.

Model 5 includes a control for the (log) average number of hours worked per week in year $t-1$. If workers have both higher weekly earnings and a higher risk of workplace injury simply because they are at work more hours each week, then failing to control for hours may bias the estimated effect of weekly earnings (and benefits, which depend on these earnings) upward. Controlling for work hours reduces the benefit and wage elasticities somewhat, and we estimate a positive relationship between hours worked and WC receipt. ${ }^{21}$

Finally, our estimates of the benefit, wage, and tax coefficients may be biased if they are correlated with omitted variables like other family income or assets. Other things equal, a worker with greater income or assets outside his labor earnings will be less likely to file a claim for WC if there are positive costs (like transaction costs or stigma) because the worker can depend on these forms of self-insurance to smooth consumption. In model 6 , we include (log) earnings of other family members, $(\log )$ income from interest, dividends, and net rentals, and (log) estimated home equity in $t-1$. The key results do not change.

In short, the initial results tell a fairly consistent story. Benefit generosity appears to have a positive effect on WC receipt; we find benefit elasticities in the range of 0.4 to 0.5 . These estimates are appreciably smaller than the analogous results derived in Krueger (1990) but are consistent with the majority of estimates provided elsewhere in the literature. ${ }^{22}$

\section{Disentangling the Effects of Wages and Benefits}

An important concern that has been overlooked by previous researchers is that the key independent variable of interest, an individual's weekly WC

\footnotetext{
${ }^{21}$ In results not shown, we include a part-time dummy variable instead of (log) hours worked per week. We estimate a negative effect of part-time status on WC receipt, but the resulting estimates of key coeffcients are very similar to those presented. We also consider the possibility that there is a threshold effect of working more than 50 hours per week, since overtime work has been shown to be associated with a greater risk of injury. We do not find evidence of such an effect.

We also consider union membership and firm size, two additional job characteristics that may be correlated with the probability of WC receipt as well as the level of WC benefits. Hirsch et al. (1997) provide evidence that the elasticity of WC receipt with respect to benefits is larger for union members than nonunionized workers. Data on union membership is available in the March CPS for individuals in outgoing rotation groups beginning in 1982. We estimate model 5 for this sample, with and without an indicator for union membership. We find a positive coefficient on union membership but only a slight reduction in the benefit elasticity (from 0.300 to 0.254 ). Since larger firms are more tightly experience rated and more likely to self-insure, firm size may also be correlated with benefits and affect the probability of WC receipt. Measures of firm size are available in the March CPS beginning in 1988. We estimate model 5 for the period from 1988 to 2003 with and without controls for firm size, but the estimated benefit elasticity changes only negligibly (from 0.611 to 0.609 ). Full results available upon request.

${ }^{22}$ We also examined responsiveness to benefit levels among a subset of blue-collar workers, a group with higher mean participation than the full sample $(0.025$ versus 0.013$)$. We find the estimated benefit elasticity for this group is 0.399 , which is on the low end of our estimates for the pooled sample. All subsequent results for blue-collar workers were qualitatively similar to those for the full sample.
} 
benefit entitlement, is a direct function of his earnings history (i.e., of his average weekly earnings over a subset of the 52-week pre-injury period). Without controlling carefully for this history, analysts cannot disentangle the effects of WC generosity on participation rates from the influence of past earnings. ${ }^{23}$

We expect these earnings to influence the decision of WC take-up directly, as a worker compares weekly earnings and marginal disutility from work to the benefits he or she would receive under WC. Past weekly earnings, however, may also indirectly affect the decision to receive WC because they may capture commitment to the labor force or represent the resources outside of WC that are available to a worker.

We take several approaches to control more flexibly for the influence of an individual's prior earnings on the likelihood he receives WC. Intuitively, the flexible earnings controls are intended to remove differences in WC participation propensities across people with different earnings. Identification comes from differences across state-years in the relative treatment of individuals with different earnings, not from the overall generosity of states.

\section{Controlling for the Influence of Earnings on Both WC Benefits and WC Receipt}

In the existing research on WC, there are two common approaches to controlling for the influence of earnings on WC claiming. The first is to use the effective (pre- or post-tax) replacement rate as the key independent variable; however, this does not allow us to separately identify the effects of benefit generosity and of lagged earnings on WC receipt. The second is to enter the components of the (log) replacement rate separately, including only a linear control for (log) weekly earnings in $t-1$ and forcing the relationship between earnings and WC participation to be the same at all points along the earnings distribution.

We have chosen the latter approach throughout in order to allow benefits and past earnings (as well as perceived taxes) to have different impacts on the likelihood of WC receipt. But because we do not know the particular form of the relationship between earnings and the WC participation decision, we examine the relationship between past earnings and WC receipt more closely.

Figure 3 shows the mean residuals from model 6 across earnings categories. ${ }^{24}$ For each of $14 \$ 100$-earnings categories, we plot the difference between the observed rate of WC receipt and the rate of WC receipt predicted by the estimates from model 6 (in Table 3). We also use locally weighted scatterplot smoothing (LOWESS) to trace a curve between these points. Figure 3 shows an inverse u-shaped relationship between prior earnings and the

\footnotetext{
${ }^{23}$ Anderson and Meyer (1997) recognize this problem in the context of UI and control for the influence of an individual's earnings history using a flexible spline in past earnings.

${ }^{24}$ Cameron and Trivedi (2005) refer to these as the "raw" residuals of the probit model.
} 
Figure 3. Observed Minus Predicted Probability of WC Receipt, by Earnings Category (Scatter Plot and LOWESS Smoothed Curve)

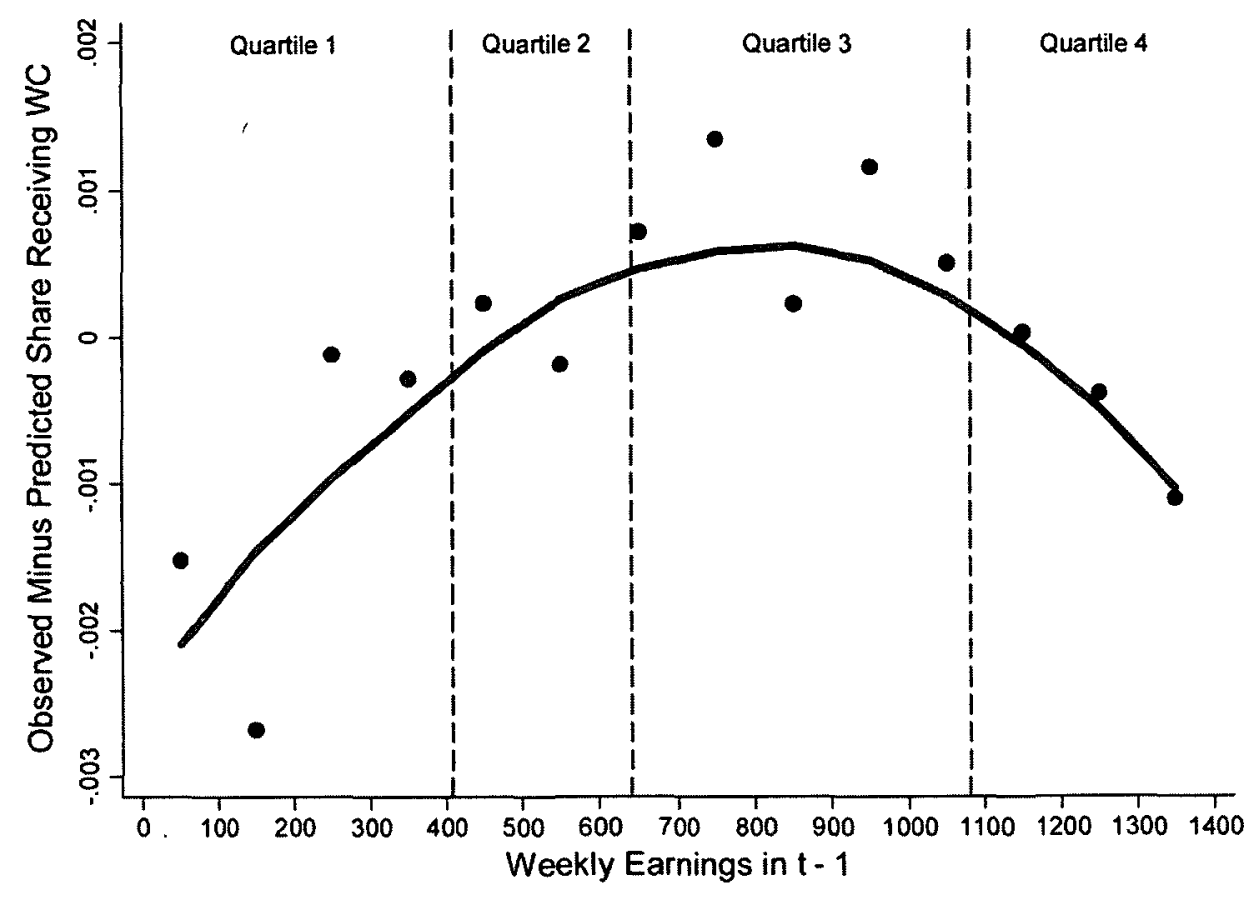

Source: Authors' calculations from CPS Sample.

residuals from model 6 . This suggests that a linear control in earnings, as in the models in Table 3, fails to pick up the relationship between prior earnings and WG receipt.

Therefore, in Table 4 we control more flexibly for the influence of past earnings on WC claiming. We begin by including a simple quadratic in an individual's prior earnings in column 2. (The naive results from our preferred specification, model 6 , are included in the first column for comparison.) The results indicate concavity in the relationship between earnings and WC receipt: WC receipt increases with earnings, but at a decreasing rate. When we control for earnings in this way, the coefficient on benefits and the estimated benefit elasticity both drop by more than half.

Because the inverse u-shaped pattern of the relationship between earnings and the rate of WC receipt may not be captured by the quadratic, we next include a 4-piece linear spline in earnings. ${ }^{25}$ The results are presented in column 3. We choose quartiles of the earnings distribution as knot points. The effect of a worker's (log) wage in $t-l$ on the probability he or she receives WC in $t$ is assumed to be piecewise linear on 4 segments, and each

\footnotetext{
${ }^{25}$ Generally speaking, let the $L-1$ selected quantiles of $\ln \left(\right.$ wage $\left._{i, t-1}\right)$ equal $K W_{2}, \ldots K W_{L}$. Then the linear spline is formed by entering as regressors the variables $W_{1}, \ldots W_{\mathrm{L}}$, where $W_{1}=\min \left(\ln \left(\right.\right.$ wage $\left.\left._{\mathrm{i}, t-1}\right), K W_{2}\right)$, and $W_{\mathrm{j}}=\max \left(\min \left(\ln \left(\right.\right.\right.$ wage $\left.\left.\left.\left._{i, t-1}\right)-K W_{j}\right), K W_{j+1}-K W_{j}\right), 0\right)$ for $j=2, \ldots L-1$, and $W_{\mathrm{L}}=\max \left(\ln \left(\right.\right.$ wage $\left._{i, t-1}\right)$ $\left.-K W_{\mathrm{L}}\right), 0$ ).
} 
Table 4. Disentangling the Effects of Wages and Benefits on WC Receipt

\begin{tabular}{|c|c|c|c|c|}
\hline VARIABLES & $\begin{array}{c}(1) \\
\text { Basic } \\
\text { Model }\end{array}$ & $\begin{array}{c}\text { (2) } \\
\text { Quadratic in } \\
\text { Earnings }\end{array}$ & $\begin{array}{c}\text { (3) } \\
\text { Earnings } \\
\text { Spline }\end{array}$ & $\begin{array}{c}\text { (4) } \\
\$ 100 \text { Earnings } \\
\text { Categories }\end{array}$ \\
\hline Log (Weekly WC benefit) & $\begin{array}{l}0.199 * * * \\
(0.041)\end{array}$ & $\begin{array}{l}0.102 * * \\
(0.050)\end{array}$ & $\begin{array}{c}0.035 \\
(0.058)\end{array}$ & $\begin{array}{l}-0.007 \\
(0.055)\end{array}$ \\
\hline Log (Weekly Earnings) ${ }_{t-1}$ & $\begin{array}{l}-0.124^{* * *} \\
(0.038)\end{array}$ & $\begin{array}{l}0.876^{* * *} \\
(0.311)\end{array}$ & & \\
\hline Log (Weekly Earnings) $)_{t-1}$ Squared & $-0.073^{* * *}$ & $(0.023)$ & & \\
\hline Earnings Spline: & & & $\begin{array}{c}0.112 * \\
(0.062)\end{array}$ & \\
\hline W2 & & & $\begin{array}{c}0.040 \\
(0.083)\end{array}$ & \\
\hline w3 & & & $\begin{array}{c}0.008 \\
(0.080)\end{array}$ & \\
\hline W4 & & & $\begin{array}{l}-0.307^{* * *} \\
(0.070)\end{array}$ & \\
\hline Weekly Earnings $<\$ 100$ & & & $-0.277^{*}$ & $(0.142)$ \\
\hline Weekly Earnings $\$ 100-\$ 200$ & & & $-0.252 * * *$ & $(0.082)$ \\
\hline Weekly Earnings $\$ 200-\$ 300$ & & & -0.063 & $(0.048)$ \\
\hline Weekly Earnings $\$ 300-\$ 400$ & & & -0.035 & $(0.033)$ \\
\hline Weekly Earnings $\$ 400-\$ 500$ & & & -0.003 & $(0.030)$ \\
\hline Weekly Earnings $\$ 500-\$ 600$ & & & - & \\
\hline Weekly Earnings $\$ 600-\$ 700$ & & & 0.034 & $(0.025)$ \\
\hline Weekly Earnings $\$ 700-\$ 800$ & . & & 0.056 & $(0.036)$ \\
\hline Weekly Earnings $\$ 800-\$ 900$ & & & 0.025 & $(0.038)$ \\
\hline Weekly Earnings $\$ 900-\$ 1000$ & & & 0.038 & $(0.042)$ \\
\hline Weekly Earnings $\$ 1000-\$ 1100$ & & & 0.013 & $(0.029)$ \\
\hline Weekly Earnings $\$ 1100-\$ 1200$ & & & -0.010 & $(0.053)$ \\
\hline Weekly Earnings $\$ 1200-\$ 1300$ & & & -0.033 & $(0.046)$ \\
\hline Weekly Earnings $>\$ 1300$ & & & $-0.108 * *$ & $(0.047)$ \\
\hline $\log (1-\operatorname{tax})$ & $\begin{array}{r}0.076 \\
-(0.062)\end{array}$ & $\begin{array}{r}0.087 \\
-(0.062)\end{array}$ & $\begin{array}{r}0.114^{*} \\
(0.065)\end{array}$ & $\begin{array}{r}0.118^{*} \\
-(0.065)\end{array}$ \\
\hline Benefit.elasticity & 0.511 & 0.262 & 0.089 & -0.017 \\
\hline Number of Obs. & 269,514 & 269,514 & 269,514 & 269,514 \\
\hline
\end{tabular}

Notes: All models include the full set of controls included in model 6 of Table 3. That is, they include controls for gender by marital status interactions, age, years of schooling, race, weekly hours worked in $t$ -1 , lagged earnings of other family members, lagged interest income, estimated home equity, occupation/industry dummies, and state and year fixed effects. Standard errors are clustered by state in alt models. The knot points (in $2002 \$$ ) are $\$ 408, \$ 640$, and $\$ 971$. 
coefficient represents the slope on a particular segment. ${ }^{26}$ Adding the fourpiece spline in lagged $(\log )$ weekly earnings reduces the estimated responsiveness of claims to variation in WC benefits dramatically. Now a $10 \%$ increase in the level of WC benefits is associated with an increase in claims frequency of less than 1 percent. Although our models are similar to those used in previous research, they may be subject to the concern that adding the earnings spline leaves the model without sufficient variation to identify the benefit elasticity. At a glance, this does not seem to be the case; the standard error on the benefit coefficient increases only negligibly from column 2 to column 3. Furthermore, the $95 \%$ confidence interval on our benefit coefficient in the spline specification suggests an upper bound on the benefit elasticity that is substantially smaller than the benefit elasticity estimated by the naive model.

The coefficients on the segments of the spline reveal a relationship between earnings and $\mathrm{WC}$ receipt that is not captured by the linear control for wages and is consistent with the patterns displayed in Figure 3. The earnings effect is positive and significant for the bottom quartile, statistically no different from zero for the second and third quartiles, and strongly negative for the top quartile of the wage distribution. We would expect a positive coefficient on earnings for the lowest quartile $(0.112)$ if the very lowest earners are largely uninformed about the WC system and their eligibility, whereas workers near the top of that bottom earnings quartile are more likely to be unionized or have worked long enough to have become informed about $\mathrm{WC}$ and their rights.

The large negative effect of earnings on WC receipt for the top quartile may result from substantial decreases in the risk of on-the-job injury as earnings get very high, especially if our occupation dummies are not perfectly capturing differences in the degree of risk associated with the jobs of high earners. Also, other forms of self-insurance (e.g., private disability insurance and paid sick leave) that would decrease the probability of a WC claim are increasingly available to workers with the very highest earnings. ${ }^{27}$

To produce the results in column 4, we impose even fewer constraints on the relationship between prior earnings and WC receipt. We include categorical earnings variables that equal 1 for workers with earnings in each of the corresponding $\$ 100$ bins of the earnings distribution (the omitted category is earnings between $\$ 500$ and $\$ 600$ ). As with the previous specification, the coefficient on the benefits variable is close to zero and not statistically significant. ${ }^{28}$

\footnotetext{
${ }^{26}$ Expanding the spline to 5, 8, and 10 pieces had no discernible effect on the benefit coefficient.

${ }^{27}$ Including two-digit controls for occupation or industry-specific time trends did not change the results.

${ }^{28} \mathrm{As}$ we have mentioned, the standard errors on the benefit coefficient remain stable across the columns of Table 4. One concern about the inclusion of state fixed effects and the flexible earnings controls, however, might be that it does not leave enough variation in the benefit variable to identify benefit effects. The variance inflation factor for model 4 is 9.0 , which is below the conventional threshold of 10.0. This suggests there is sufficient within-state variation in benefit levels, even after controlling for categories of earnings.
} 
The pattern on the earnings coefficients is largely consistent with the spline coefficients and the inverse u-shaped pattern observed in Figure 3. Workers earning less than $\$ 100$ are the least likely to claim WC benefits, even after controlling for hours worked per week. Then, the coefficients increase (i.e., become less negative) over the first five earnings categories, remain roughly the same over the next four intervals, and decrease over the last few earnings categories (i.e., for earnings greater than $\$ 1,100$ ). ${ }^{29}$

In conclusion, irrespective of our method for controlling more flexibly for prior earnings, we find that the estimated benefit elasticity drops dramatically. By controlling more flexibly for the influence of earnings on WC participation and allowing the earnings-WC relationship to vary for workers at different points along the earnings distribution, we aim to ensure that our estimate of the benefit elasticity is not attributing some of the impact of earnings, which policymakers clearly cannot control, to benefits.

This estimate of the average relationship between benefits and WC claims is directly comparable to the much larger estimates of the benefit elasticity documented in previous research. Therefore, at this point we do not include flexible controls for benefits as well. And these findings may have important implications for the literature: Clearly, they suggest that researchers must think carefully about controlling for the influence of past earnings on program participation when studying programs in which benefits are a function of these earnings. This may be true even for many natural experiments in WC (e.g., changes in the maximum benefit), wherein the treatment and control groups differ according to earnings. ${ }^{30}$

More broadly, the resulting benefit elasticity (smaller than 0.1 ) suggests that the effect of increased WC generosity on the number of WC claims (or moral hazard) may warrant less concern than it is typically expressed by economists and policymakers. At the very least, once we control for differences in WC claim propensities across the earnings distribution, we cannot reject the null hypothesis that the impact of variation in WC benefits on the frequency of receipt is zero.

\section{Effects of WC Benefits across the Earnings Distribution}

The estimates we have presented suggest important differences in the relationship between earnings and WC claiming at different points in the earnings distribution. These results, however, are from models that hold the relationship between benefits and WC receipt constant across the earnings distribution. In this section, we explore how the relationship between benefits and WC receipt varies across quartiles of the earnings distribution. To do this, we examine these relationships as they change over the quartiles of the earnings distribution using three different parameterizations of WC benefit generosity.

\footnotetext{
${ }^{29}$ The same qualitative conclusions hold when we include $\$ 100$ bins up to $\$ 1,700$, or when we include dummy variables for deciles of the earnings distribution.

${ }^{30}$ See, for example, Meyer, Viscusi, and Durbin (1995) and Neuhauser and Raphael (2004).
} 


\section{The Expected WC Benefit}

We begin by estimating model 6 separately for workers in the different quartiles of the earnings distribution (see Table 5). Note first that the pattern of coefficients on (log) earnings across the earnings quartiles is consistent with the pattern of coefficients on the earnings spline variables.

It is interesting that, for workers in the lowest quartile, we estimate a significant, negative relationship between WC benefits and WC receipt, as shown in the top panel of the table. Recall that these estimates incorporate both the incentive effects of increased benefits for workers and those for firms. The evidence in Card and McCall (2009) provides a reasonable explanation for this seemingly anomalous result. The authors find that employers are more likely to deny claims for low-income workers because these workers are less likely to fight back. With experience-rated premiums, firms' denials or discouragement of low earners' claims for WC will increase as benefits increase, since paying these claims will raise insurance costs for employers. Bernhardt et al. (2009) also provide evidence that low-wage earners are far less likely to file a successful claim for WC than are higher earners. Furthermore, $50 \%$ of low-wage earners in their sample experienced an illegal employer reaction when they reported an injury, including being fired or instructed not to file for WC. Our findings consistently indicate fundamentally different relationships among earnings, benefits, and WC claiming for low earners than for higher earners. We suggest that future research focus on better understanding this relationship and the experience of low earners within the WC system. Interestingly, estimating the model separately for men and women reveals that females seem to be driving this result for low earners; that is, the coefficient on benefits for women is strongly negative, while for men it is small and positive but not statistically different from zero. Thus, it may also be important for future studies to consider possible gender differences in WC claiming behavior, perhaps especially among low earners.

The estimated coefficient on the benefit variable is small and positive, but not statistically significant for the next two quartiles, and is approximately zero for the top earnings quartile. The majority of workers in the second and third earnings quartiles face the same replacement rate of two-thirds. Since wages and benefits are so highly correlated for these workers, we are not surprised that the coefficients on wages and earnings are not statistically significant.

\section{Legislated WC Program Parameters}

Our estimates to this point-and the greater part of the estimates in the literature-have examined how responsive workers are to a change in the generosity of a worker's expected WC benefit, given his or her earnings. But the elasticity of WC receipt with respect to expected benefits may not be the policy parameter of most interest, since policymakers do not simply raise 


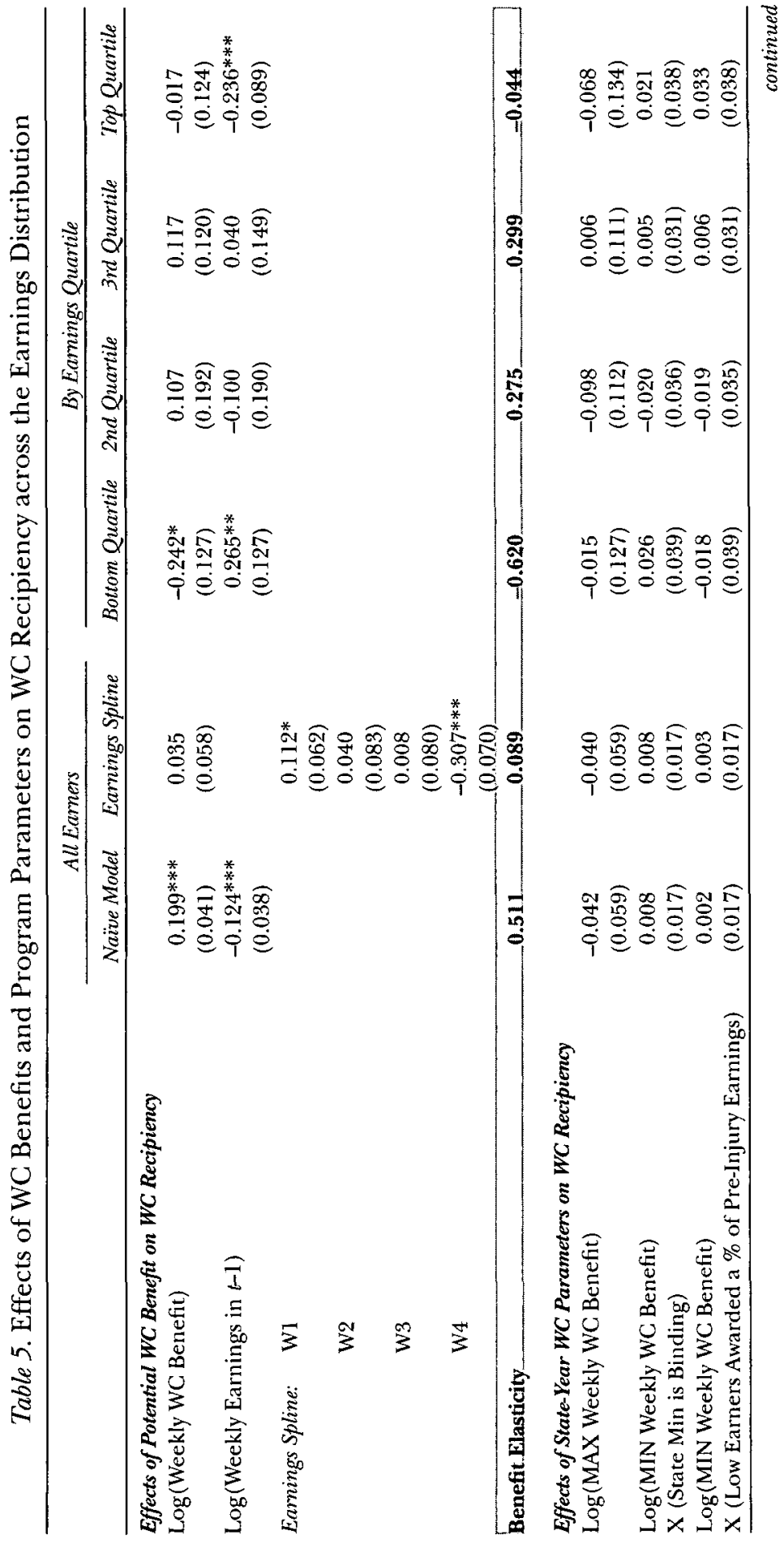




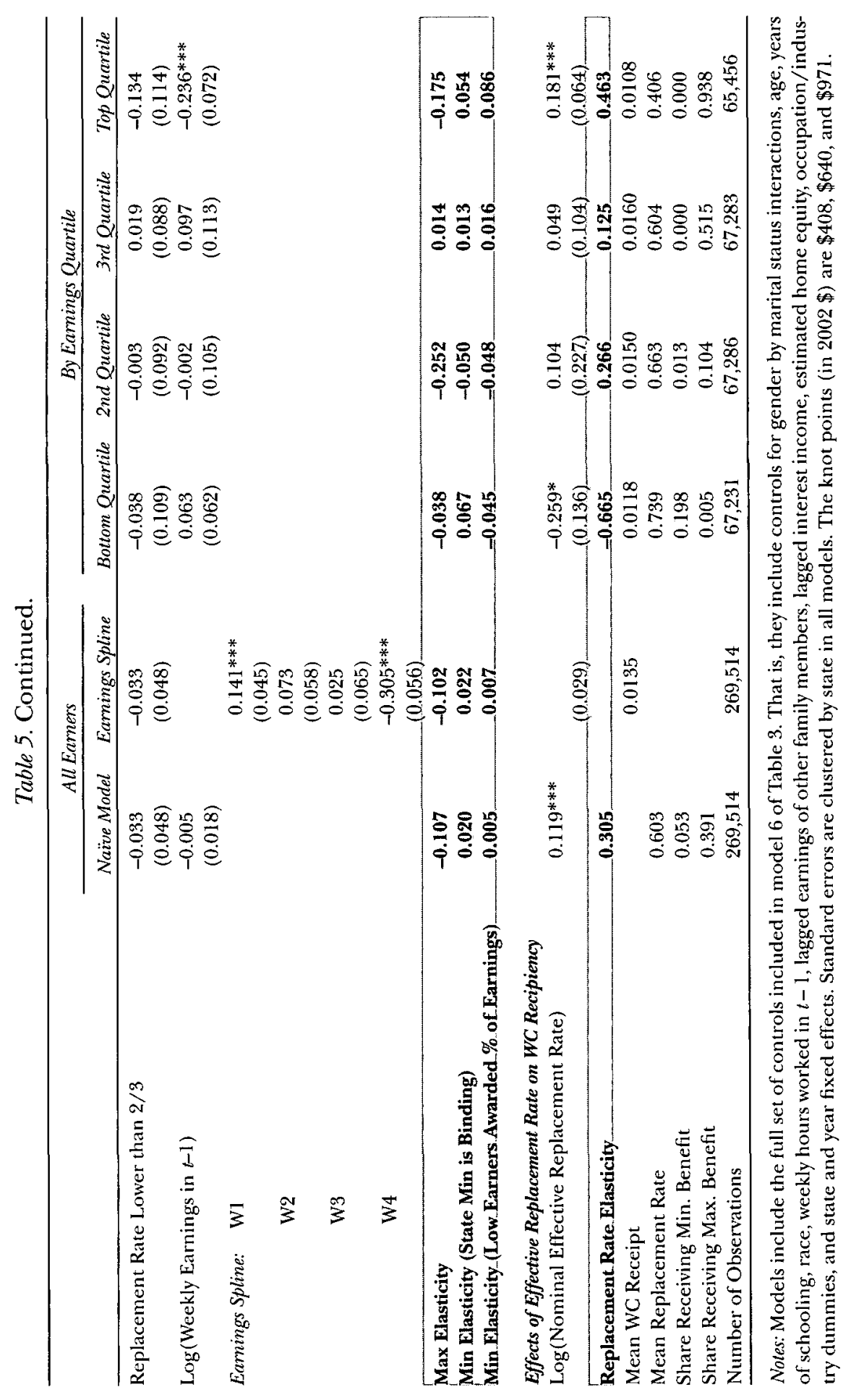


expected benefits by $10 \%$. Rather, policymakers have three levers at handthe maximum benefit, the minimum benefit, and the replacement rate.

In the second panel of Table 5 we explore the responsiveness of WC participation to variation in these WC program parameters. We include the $(\log )$ max weekly benefit and separately include the $(\log )$ min weekly benefit for the two different ways states treat the minimum. We distinguish between states that have minimum benefits that are binding and where workers with earnings below that minimum value receive the minimum benefit (i.e., more than $100 \%$ of their pre-injury earnings) and those states that effectively have no minimum benefit or that award workers their full weekly earnings if below a certain level. Finally, we include an indicator for states with replacement rates below two-thirds.

For the pooled sample, whether we employ a linear control for earnings or the 4-piece spline, the coefficients are close to zero and not statistically significant. Note also that the coefficients on the earnings spline variables in column 2 are very similar to those from the model that uses the expected WC benefit as the key independent variable. In columns 3 through 6 , we show these relationships across quartiles of the earnings distribution. We would expect that the minimum benefit is more likely to be binding for those in the bottom quartile, but we find no statistically significant relationship between the minimum benefit and WC receipt. This is likely because only $19.8 \%$ of workers in the bottom quartile receive the minimum benefit. In quartiles 2 and 3, where we would expect the replacement rate to matter the most, we find no evidence of a relationship between the replacement rate and WC receipt. Of course, with state fixed effects included to capture important time-invariant state characteristics that affect the probability of WC receipt, little within-state variation remains in legislated replacement rates. Among the highest earners, we expect the maximum to be most meaningful but find no relationship.

\section{The Effective Replacement Rate}

Legislated changes in maximum and minimum benefit levels essentially amount to changes in the effective replacement rate over identifiable parts of the earnings distribution. In the third panel of Table 5, we estimate the relationship between $W C$ receipt and the pretax replacement rate (i.e., the expected weekly WC benefit divided by the worker's pre-injury weekly earnings).

For the pooled sample, the estimated effect of a worker's replacement rate on the likelihood of claiming WC is positive: A $10 \%$ increase in the replacement rate is associated with a $3 \%$ increase in WC receipt. As in our earlier results, however, the average elasticity for the pooled sample conceals important differences across the earnings distribution.

Over the first three earnings quartiles, the results are qualitatively very similar to those in the top panel of the table, where the expected WC benefit is the key independent variable. In the first earnings quartile, a higher 
replacement rate is associated with a lower probability of a WC claim. This is consistent with the result in the top panel, when we include the components of the replacement rate separately. While we have offered some suggestive evidence from the literature to explain this finding, we believe that WC receipt among low earners is a topic that warrants further research. Over the next two quartiles, the relationship between the effective replacement rate and WC receipt is small and positive but not statistically significant.

Last, while the strong positive coefficient on the (log) replacement rate in the top earnings quartile initially appears to contradict our earlier findings for high earners, recall that replacement rates are higher at higher levels of benefits and lower levels of earnings. As we show in the top panel, higher earners are not responsive to higher benefits. Nevertheless, we find throughout that for the top earnings quartile, the likelihood of WC is negatively related to earnings and would thus be positively related to the replacement rate. Our main qualitative conclusions are upheld.

\section{WC Benefit Levels and Claim Incidence Since 1990}

Though the majority of research on incentive effects in WC focuses on pre-1990s data, dramatic changes to WC have occurred since 1990. Before 1990, WC recipients had higher potential benefits and higher weekly earnings, on average, than nonrecipients. But after 1990, WC recipients faced lower potential benefits and had lower weekly earnings than did nonrecipients. Moreover, legislated benefit generosity increased during the post-1990 period, whether measured by the real maximum benefit or the average nominal replacement rate, but the frequency of WC claims dropped in half (see Figures 1 and 2). These trends might indicate a shift in worker responsiveness to benefit levels, or they might reflect other changes that would be expected to decrease WC claims-namely, improvements to workplace safety and changes to the WC system that made it harder for injured workers to receive benefits.

In addition to improvements in workplace safety in the 1990s, two-thirds of all states enacted some type of reform to their WC system during that decade. Many states enacted stiff penalties for fraudulent claiming, granted employers the privilege of selecting which doctor would treat a workplace injury, required objective medical evidence of a workplace injury, limited compensability of injuries that merely aggravated pre-existing conditions, or introduced workplace safety and health programs (see, e.g., Conway and Svenson, 1998). Each of these reforms is expected to decrease the number of WC claims, either by discouraging workers from filing claims or making it harder for claims to be accepted. ${ }^{31}$ The evidence on the effect of these re-

\footnotetext{
${ }^{31}$ Furthermore, these policy changes and employer efforts to get injured workers back to work may have led to a reduced benefit elasticity, if these changes diverted workers suffering soft tissue injuries (which are hard to verify and are more responsive to changes in benefit generosity) from claiming WC.
} 
forms on the WC program is mixed. Guo and Burton (2010) find that these types of reforms led to a decline in the dollar amount of benefits paid after $1990,{ }^{32}$ and Boden and Ruser (2003) find a modest effect of these reforms on workplace injuries. In contrast, Ruser et al. (2004) find no effect of these reforms on $\mathrm{WC}$ receipt.

In Table 6 , we examine the relationship between WC receipt and benefits in the pre-1990 and post-1990 periods. We display estimates from the model with the earnings quadratic and the earnings spline specification for the pooled sample and for both periods separately. These results confirm our suspicions that the years since 1990 have been importantly different for WC than were the previous decades, and they indicate how crucial it is to consider the influence of earnings on both WC participation and WC benefits. When we include a quadratic in earnings, the estimated benefit elasticity is similar in both periods, but our estimates from the inclusion of the 4-piece earnings spline tell a different story. In the pre-1990 period, including the earnings spline reduces the estimated benefit elasticity to 0.310 ; the benefit coefficient remains positive and statistically significant. In contrast, controlling flexibly for past earnings reduces the benefit elasticity for the post-1990 period to approximately zero, and the probit coefficient on benefits is no longer statistically significant. ${ }^{33}$

This decline in responsiveness could reflect employers' reactions to rising WC costs in the 1980s: BLS data on injuries involving restricted workdays but not lost workdays indicate an increase in workplace accommodation of injured workers during this period (Ruser 1999). Finally, we also suspect that some of the decline in $W C$ receipt may be explained by changes in the relationship between earnings and decisions regarding WC, especially near the top of the earnings distribution.

\section{Conclusions}

Our study offers new evidence on the magnitude of incentive effects in state WC programs. Our findings suggest a positive effect of benefit levels on WC claims, but the magnitude of this relationship depends crucially on

\footnotetext{
${ }^{32}$ This study also provides evidence that the responsiveness of BLS injury rates to variation in WC benefits was close to zero, both in the 1990 s and the earlier period. Our work differs from Guo and Burton's in several substantive ways. Their study uses aggregate state-level data and injury rates as the dependent variable. As expected, studies that use the injury rate as the dependent variable tend to find smaller effects of benefits than studies that examine the frequency of WC claims and receipt. Finally, they do not include a measure of the weekly wage or earnings in the state. Our study shows the importance of controlling carefully for prior earnings when estimating the benefit elasticity.

${ }^{33}$ This result may also arise because of important changes to workplace safety and the WC system. To better control for improved workplace safety, we incorporate 2-digit occupation dummies. Our main findings are robust to this change. Next, we consider the legislated policy reforms examined in Boden and Ruser (2003) and Ruser et al. (2004). Information on these policy changes is available only from 1990 through 1997. Within this subset of years, expanding the specification to include an indicator for whether a state has enacted any of these policy changes has little impact on the estimated benefit elasticity.
} 


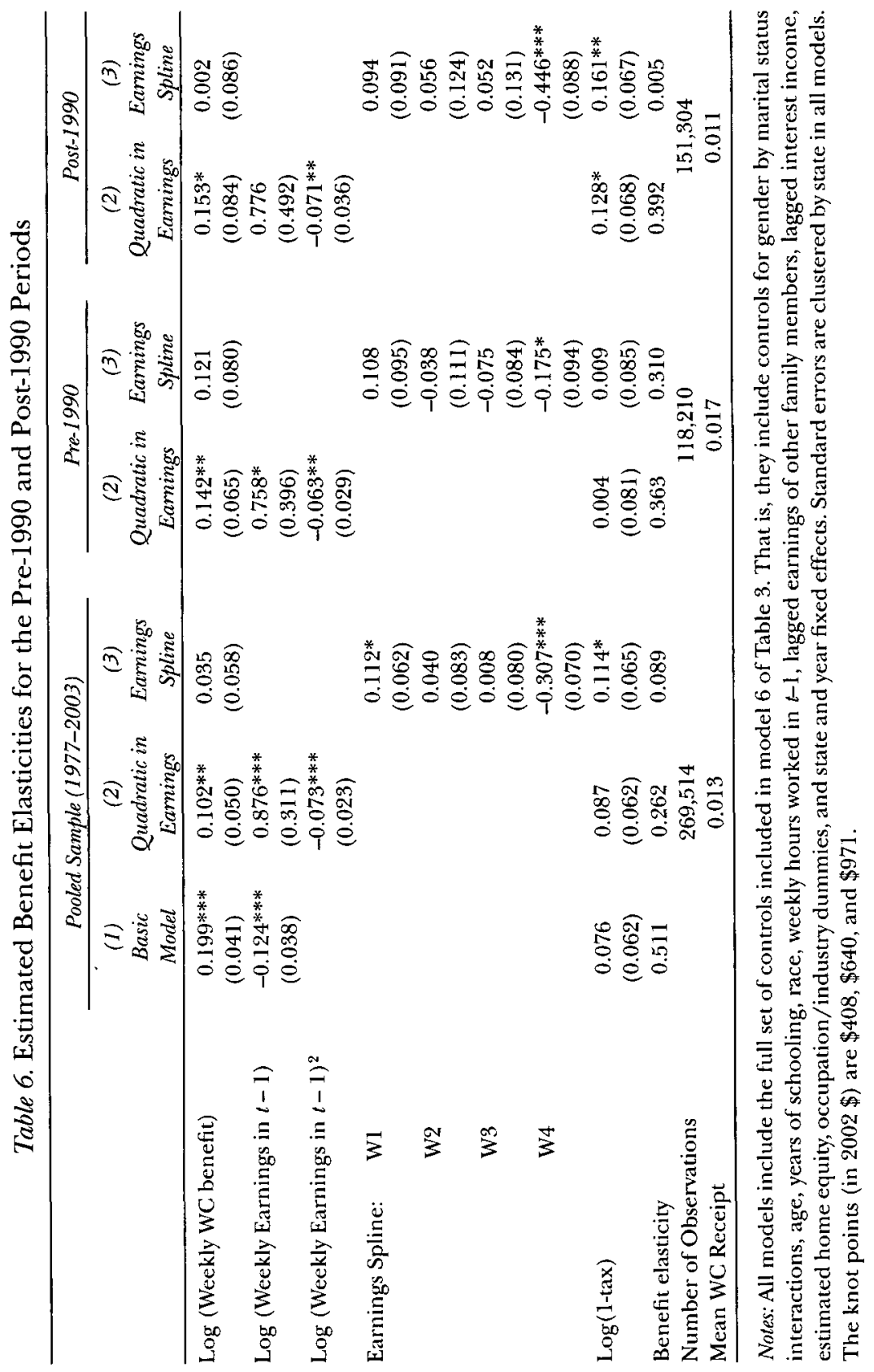


how we control for the confounding influence of past earnings on both benefits and the probability of a WC claim.

Following an approach similar to that used in previous research yields estimates of the elasticity of WC receipt with respect to benefits of approximately 0.4 or 0.5 , depending on the specification. But when we expand upon previous work to include flexible controls for the influence of past earnings on WC claiming propensities we arrive at a very different conclusion about the relationship between WC benefits and the frequency of WC receipt. Whether we include a simple linear spline in past earnings or indicators for several categories of earnings, we estimate a benefit elasticity that is smaller than 0.1 , which suggests that a 10 percent increase in benefits would cause less than a 1 percent increase in the number of WC recipients.

This finding is corroborated by our evidence on the responsiveness of WC claims to legislated WC program parameters. We find no relationship between the frequency of WC receipt and key WC parameters, like the maximum, minimum, and replacement rate, even within quartiles of the earnings distribution for which these parameters are most relevant.

Finally, our initial results conceal important differences between the pre1990 and post- 1990 periods. We find that WC participation was significantly less responsive to changes in benefits in the post-1990 period than in earlier years. We also suspect that changes in the wage distribution may help explain this finding; we leave this as an avenue for future research.

The implications of our findings are threefold: First, in order to identify precisely the effect of variation in WC benefits on program participation, researchers must think carefully about controlling for the influence of past earnings on WC claims propensities. This caveat also applies to research on other programs in which benefits are a direct function of previous earnings and for some natural experiment approaches that are based on comparing workers with high and low earnings. Second, while estimates of the average benefit elasticity are common in the literature, we show that the average effect can conceal important differences in claiming behavior across the earnings distribution. Our results consistently show that low earners are less likely to receive WC when benefits are more generous, a finding that should be the focus of further study. Third, the rather limited responsiveness of WC participation to changes in benefits indicated by our estimates suggests that the distortionary labor supply effects of WC, at least at this margin, may not warrant as much concern as economists and policymakers typically devote to them. According to our findings, states may increase program generosity at a lower cost than implied by previous estimates. Likewise, cost savings from legislated decreases in benefits are likely to be less substantial than previously thought.

\section{References}

Anderson, Patricia M., and Bruce D. Meyer. 1997. Unemployment insurance take-up rates and the after-tax value of benefits. Quarterly Journal of Economics, 112(3): 913-37.

Bernhardt, Annette, Ruth Milkman, Nik Theodore, Douglas Heckathorn, Mirabai Auer, 
James DeFilippis, Ana Luz González, Victor Narro, Jason Perelshteyn, Diana Polson, Michael Spiller. 2009. Broken laws, unprotected workers: violations of employment and labor laws in America's cities. UCLA Institute for Research on Labor and Employment Report.

Biddle, Jeff, and Karen Roberts. 2003. Claiming behavior in workers' compensation. Joumal of Risk and Insurance, 70(4): 759-80.

Boden, Leslie I. and John W. Ruser. 2003. Workers' compensation 'reforms', choice of medical care provider, and reported workplace injuries. Review of Economics and Statistics, 85(4): 923-29.

Butler, Richard F. and John D. Worrall. 1983. Workers' compensation: benefit and injury claims rates in the seventies. Review of Economics and Statistics, 65(4):580-89.

- 1991. Claims reporting and risk bearing moral hazard in workers' compensation. Journal of Risk and Insurance, 58(2): 191-204.

Cameron, A. Colin, and Pravin K. Trivedi. 2005. Microeconometrics: Methods and Applications. New York: Cambridge University Press.

Card, David, and Brian P. McCall. 1996. Is workers' compensation covering uninsured medical costs? Evidence from the 'Monday Effect'. Industrial and Labor Relations Review, 49(4): $690-706$.

- 2009. When to start a fight and when to fight back: Liability disputes in the workers' compensation system. Journal of Labor Economics, $27(2)$ : 149-78.

Chelius, James R. 1982. The influence of workers' compensation on safety incentives. Industrial and Labor Relations Revierw, 35 (2): 235-42.

Chelius, James R., and Robert S. Smith. 1983. Experience-rating and injury prevention. In John D. Worrall, ed., Safety and the Work Force, pp. 128-37. Ithaca: ILR Press.

Chernew, Michael, Philip DeCicca, and Robert Town. 2008. Managed care and medical expenditures of Medicare beneficiaries. Journal of Health Economics, 27(6): 1451- 61.

Conway, Hugh, and Jens Svenson. 1998. Occupational injury and illness rates, 1992-1996: Why they fell. Monthly Labor Review, 121 (11): 36-58.

Fortin, Bernard, and Paul Lanoie. 1998. Effects of workers' compensation: A survey. CIRANO Working Paper 98s-04.

Guo, Xuguang (Steve) and John F. Burton, Jr. 2010. Workers' compensation: Recent developments in moral hazard and benefit payments. Industrial and Labor Relations Review, 63(2): $340-55$.

Hirsch, Barry T., David A. Macpherson, and J. Michael Dumond. 1997. Workers' compensation recipiency in union and nonunion workplaces. Industrial and Labor Relations Review, 50(2): 213-36.

Krueger, Alan B. 1990. The incentive effects of workers' compensation. Joumal of Public Economics, 41(1): 73-99.

- 1991. Workers' compensation and the duration of workplace injuries. Unpublished paper, Princeton University.

Krueger, Alan B. and John Burton. 1990. The employers' cost of workers' compensation insurance: magnitudes, determinants, and public policy. NBER Working Paper no. 3029. Cambridge, MA: National Bureau of Economics Research.

Krueger, Alan B., and Bruce D. Meyer. 2002. Labor supply effects of social insurance. NBER Working Paper no. 9014. Cambridge, MA: National Bureau of Economic Research.

Lakdawalla, Darius, Robert Reville, and Seth Seabury. 2007. How does health insurance affect workers' compensation filing? Economic Inquiry, 45 (2): 286-303.

Madrian, Brigitte C. and Lars John Lefgren. 1999. A note on longitudinally matching Current Population Surveys (CPS). NBER Working Paper no. T0247. Cambridge MA: National Bureau of Economic Research.

Meyer, Bruce D. 2002. Unemployment and workers' compensation programmes: rationale, design, labour supply and income support. Fiscal Studies, 23(1): 1-49.

Meyer, Bruce, W. Kip Viscusi, and David Durbin. 1995. Workers' compensation and injury duration: evidence from a natural experiment. American Economic Review, 85 (3) 322-40.

Moore, Michael J., and W. Kip Viscusi. 1989. Promoting safety through workers' compensation: The efficacy and net wage costs of injury insurance. RAND Journal of Economics, 20(4): 499-515. 
Neuhauser, Frank, and Steven Raphael. 2004. The effect of an increase in workers' compensation benefits on the duration and frequency of benefit receipt. Review of Economics and Statistics, 86(1): 288-302.

Ruser, John W. 1985. Workers' compensation insurance, experience-rating, and occupational injuries. RAND Journal of Economics, 16(4): 487-503.

- 1991. Workers' compensation and occupational injuries and illnesses. Journal of Labor Economics, 9(4): 325-50.

1998. Does workers' compensation encourage hard to diagnose injuries? Journal of Risk and Insurance, 65(1): 101-24.

1999. The changing composition of lost-workday injuries. Monthly Labor Review, 122(6): 11-17.

Ruser, John, Michael Pergamit, and Parvati Krishnamurty. 2004. Workers' compensation "reforms" and benefit claiming. U.S. Bureau of Economic Analysis Working Paper.

Sengupta, Ishita, Virginia P. Reno, and John F. Burton, Jr. 2010. Workers' Compensation: Benefits, Coverage, and Costs, 2008, New Estimates. Washington, D.C.: National Academy of Social Insurance.

Smith, Robert S. 1990. Mostly on Monday: Is workers' compensation covering off- the-job injuries? In Philip S. Borba and David Appel (Eds.), Benefits, Costs, and Cycles in Workers' Compensation. Kluwer Academic Publishers.

U.S. Chamber of Commerce. Analysis of Workers' Compensation Laws (1977-2004). Washington, D.C.: U.S. Chamber of Commerce.

U.S. House of Representatives, Committee on Ways and Means. 2004. The Green Book: Background Material and Data on Programs within the Jurisdiction of the Committee on Ways and Means, 17 th edition.

Worrall, John D. and Richard J. Butler. 1988. Experience rating matters. In Philip S. Borba and David Appel (Eds.), Workers' Compensation Insurance Pricing: Current Programs and Proposed Reforms, pp. 81-94. Boston: Kluwer Academic Press. 